\title{
Anesthesia research training: preparing for the future of our speciality
}

\author{
Sinziana Avramescu, MD, PhD $\mathbb{~ ( 1 )} \cdot$ Beverley A. Orser, MD, PhD
}

Received: 16 November 2015/Revised: 3 December 2015/ Accepted: 12 January 2016/Published online: 20 January 2016

(c) Canadian Anesthesiologists' Society 2016

\section{To the Editor,}

The report by Khan et al. ${ }^{1}$ summarizes the preferences of anesthesia residents enrolled in Canadian training programs and the factors that influenced their career choices. In all, $70 \%$ of respondents in this survey intended to pursue fellowship training, and more than half $(56 \%)$ preferred to work in an academic centre. Importantly, more than one in three of the respondents $(34 \%)$ intended to incorporate research into their careers, yet fewer than one in $25(3.7 \%)$ planned to undertake a research fellowship. The latter result suggests a "disconnect" between training expectations and career goals, given that the probability of establishing a successful research career increases with research training. ${ }^{2}$

Formal research training increases the rate of success in obtaining a faculty appointment with research responsibilities and secured research funds. ${ }^{2}$ For example, graduates of medical scientist training programs (MD-PhD) were more likely to obtain postdoctoral awards from the National Institutes of Health (NIH) (35\%) than graduates with an MD degree alone (4\%). ${ }^{2} \mathrm{MD}-\mathrm{PhD}$ graduates were

This letter is accompanied by a reply. Please see Can J Anesth 2016; 63: this issue.

S. Avramescu, MD, PhD ( $₫)$. B. A. Orser, MD, PhD

Department of Anesthesia, University of Toronto, Toronto, ON, Canada

e-mail: Sinziana.avramescu@utoronto.ca

S. Avramescu, MD, PhD - B. A. Orser, MD, PhD

Department of Anesthesia, Sunnybrook Health Sciences Centre, Toronto, ON, Canada

B. A. Orser, $\mathrm{MD}, \mathrm{PhD}$

Department of Physiology, University of Toronto, Toronto, ON, Canada also more likely to have an academic appointment with a research component (33\%) than their peers without research training $(7 \%){ }^{2}$ Interestingly, even one year of intense research training during medical school, without completion of a graduate degree, increased the chances of success in securing postdoctoral awards fivefold and the chances of holding a research appointment almost threefold. ${ }^{2}$ Other studies have shown that the majority of clinician-scientists who embarked on the MD-PhD track continued to hold academic positions (81\%), and most maintained active research programs $(82 \%)$ and had secured identifiable research funding $(61 \%){ }^{3}$ Additional information about the physician-scientist biomedical workforce in the United States can be found on the NIH website (http://report.nih.gov/workforce/psw/index.aspx).

Unfortunately, similar information about physicianscientists trained in Canada is unavailable on the Canadian Institutes of Health Research (CIHR) website. This lack of evaluative data on CIHR's training program is surprising, as is the decision by the CIHR to terminate funding for the 30 -year-old MD-PhD program. There is no alternate source of CIHR funds in place at this time. Concerns regarding this change in CIHR funding have been recognized by the international science community, ${ }^{4}$ as training future generations of clinician-scientists who will lead knowledge translation should be a key priority for health research programs.

Canadian anesthesia residents seeking to undertake graduate studies during residency training can consider participating in the Clinician Investigator Program (CIP) of the Royal College of Physicians and Surgeons of Canada (http://www.royalcollege.ca/portal/page/portal/rc/credentials/ accreditation/arps/specialty/clinician). This program was established in 1995 with the goal of crafting independent clinician-investigators with rigorous research training. 
A review of the number of anesthesia residents participating in the CIP in 2001 indicated that only one resident from the 16 anesthesia training programs had enrolled. ${ }^{5} \mathrm{~A}$ broader review of CIP, published in 2011 after the ten-year anniversary, showed that the number of anesthesia residents in the CIP program was about 22-fold lower than the number of general surgery residents. ${ }^{6}$ The majority of all trainees completed either an MSc (58\%), $\mathrm{PhD}(39 \%)$ or MEd (3\%) degree. ${ }^{6}$ Most CIP participants secured an academic appointment, pursued research projects, and published research papers. ${ }^{6}$ Interestingly, a survey of University of Toronto CIP trainees in 2011 reported that most were satisfied with completing a graduate degree during residency (92\%). They also expected to become clinician-scientists $(92 \%)$ and participate in research programs $(86 \%))^{7}$ Many CIP trainees were worried about falling behind on their clinical skills (79\%). They also raised concerns about successfully competing for research funds $(96 \%)$ and maintaining a work-family balance $(99 \%){ }^{7}$ Finally, although we attempted to determine the number of Canadian residents who received peer-reviewed fellowships and pursued graduate-level studies after residency, this information was unavailable.

Although graduate studies are not the only pathway to research training, they provide structured oversight and rigor that may not be available through less structured research programs. Anesthesia departments need welltrained researchers to support their academic missions. Talented, well-trained young investigators could begin to address the low funding levels of anesthesia departments relative to other specialities. By comparison, in the United States, internal medicine specialists secured 30 times more NIH funding than anesthesiologists. ${ }^{8}$ The report by Khan et al. ${ }^{1}$ suggests that the number of anesthesia residents seeking research training is low. Mentors need to encourage residents to undertake research training during their fellowship or residency years to allow them to achieve their career goals and advance the research mission of our speciality.

Conflicts of interest None declared.

Financial support Sinziana Avramescu was supported by a Canadian Institutes of Health Research (CIHR) Fellowship, a Clinician Scientist Transition Award from the Department of Anesthesia, University of Toronto, a Mentored Research Award from the International Anesthesia Research Society and a Canadian Anesthesiologists' Society (CAS)/Vitaid Residents' Research Grant. Beverley A. Orser was supported by operating grants from the CIHR, the CAS and the Centre for Collaborative Drug Research of the University of Toronto.

\section{References}

1. Khan J, Gilbert J, Sharma A, LeManach Y, Yee D. Perspectives of anesthesia residents training in Canada on fellowship training, research, and future practice location. Can J Anesth 2015; 62: 956-63.

2. Fang D, Meyer RE. Effect of two Howard Hughes Medical Institute research training programs for medical students on the likelihood of pursuing research careers. Acad Med 2003; 78: 1271-80.

3. Brass LF, Akabas MH, Burnley LD, Engman DM, Wiley CA, Andersen $O S$. Are MD-PhD programs meeting their goals? An analysis of career choices made by graduates of $24 \mathrm{MD}-\mathrm{PhD}$ programs. Acad Med 2010; 85: 692-701.

4. Lewinson RT, Beers CA, Capozzi LC, Iablokov V, Keough MB, Peplowski MA. The Canadian $\mathrm{MD} / \mathrm{PhD}$ training program needs reinstated support. Nat Med 2015; 21: 1111.

5. Orser BA, Miller DR. New opportunities for anesthesia research in Canada. Can J Anesth 2002; 49: 895-9.

6. Hayward CP, Danoff D, Kennedy M, Lee AC, Brzezina S, Bond U. Clinician investigator training in Canada: a review. Clin Invest Med 2011; 34: E192.

7. Ballios $B G$, Rosenblum ND. Challenges facing physician scientist trainees: a survey of trainees in Canada's largest undergraduate and postgraduate programs in a single centre. Clin Invest Med 2014; 37: E268-83.

8. Schwinn DA, Balser JR. Anesthesiology physician scientists in academic medicine: a wake-up call. Anesthesiology 2006; 104: $170-8$. 